\title{
Granular Carbides-Assisted Ultrafine-Ferrite Fabrication in the Pearlitic Steel Without Severe Plastic Deformation and Annealing
}

\author{
Han Zheng ${ }^{1} \cdot$ Liming $\mathrm{Fu}^{1} \cdot$ Xinbo $\mathrm{Ji}^{1} \cdot$ Ziyong $\mathrm{Li}^{1} \cdot$ Yanle Sun ${ }^{1} \cdot$ Sixin $\mathrm{Zhao}^{2} \cdot$ Wei Wang $\cdot$ Aidang Shan ${ }^{1}$
}

Received: 22 March 2020 / Revised: 29 April 2020 / Accepted: 21 May 2020 / Published online: 14 August 2020

(C) The Chinese Society for Metals (CSM) and Springer-Verlag GmbH Germany, part of Springer Nature 2020

\begin{abstract}
The evolution of ferrite grain and cementite lamella during cold rolling in a granular carbide-pearlite steel has been investigated. Particular attention has been given to a quantitative characterization of changes in the ferrite grains. Electron backscattered diffraction and transmission electron microscopy observations show that the ultrafine ferrite $(\sim 388 \mathrm{~nm})$ can be produced through low equivalent strain cold rolling without severe plastic deformation (SPD) and annealing. The average grain size of ferrite depends on the volume fraction, shape and distribution of granular carbides as well as interlamellar spacing of pearlite. A general explanation of granular carbides-assisted grain refinement is that the embedded carbides between natural barrier will significantly facilitate dislocation nucleation during cold rolling. Dislocation reaction occurs more drastically and quickly near these granular carbides. Such reactions promote the formation of high-angle grain boundaries. The formation of ultrafine ferrite grains and subgrains in steel after cold rolling to $\varepsilon=1.4$ strain makes the strength and ductility increased simultaneously compared with $\varepsilon=0.6$ cold-rolled steel. The results suggest a new material design strategy to obtain ultrafine-grained structure via the granular carbides assistance.
\end{abstract}

Keywords Grain refinement · Carbide $\cdot$ Pearlitic steel $\cdot$ Cold rolling

\section{Introduction}

Grain refinement is usually the focus of attention on the microstructural control of steel [1-10]. In order to fabricate ultrafine-grained structures, it is suggested that an equivalent strain of over 4 generated from severe plastic deformation (SPD) is needed [3]. In other words, the ultrafine grains cannot be fabricated without the support of imposed enormous logarithmic strain [3-5, 11-13]. In general, the efficiency of grain refinement is not only related to the external strain conditions, but also depends on the internal characteristics of material, such as initial microstructures $[14,15]$. Tsuji et al.

Available online athttp://link.springer.com/journal/40195.

Liming Fu

lmfu@sjtu.edu.cn

$\triangle$ Aidang Shan

adshan@sjtu.edu.cn

1 School of Materials Science and Engineering, Shanghai Jiao Tong University, Shanghai 200240, China

2 Central Research Institute (R\&D Center) , Baoshan Iron \& Steel Co., LTD, Shanghai, China
[16] reported that without large logarithmic strain, an nanostructure $(\sim 400 \mathrm{~nm})$ austenitic steel with very low stacking fault energy can also be obtained through heavy cold rolling and annealing. Then, the question emerges that whether there exists a way to produce ultrafine ferrite grains in steel plate without the two strategies (enormous logarithmic strain and annealing) at the same time.

Grain refinement induced by plastic deformation has been extensively investigated in various metallic materials with diverse crystallographic structures (e.g., bcc, fcc and hcp). It has been well documented and comprehensively understood that these grain refinement mechanisms are always inseparable from the individual or interactive effect deriving from phase transformations, dislocation movement and mechanical twinning [17]. For dislocation activities-dominated grain refinement, ultrafine ferrite grains cannot be easily obtained with low equivalent strain by common cold rolling. The refined structures formed during ordinary cold rolling are subdivided by low-angle grain boundaries (LAGBs) rather than high-angle grain boundaries (HAGBs) [18]. The absence of HAGBs can be attributed to restricted strains of plastic deformation [19]. Now, there are two noteworthy experimental results which can help to solve this dilemma. 
First, it has been recognized that in the steel via strain-driven grain refinement, the ferrite grain size in severely deformed pearlitic steels (like HPT [20, 21], cold drawing [1]) can be one order of magnitude smaller than that in pure iron. Specific to strain-induced microstructure evolution, it has been interpreted that multiphase materials are considerably different and more complex in comparison with single-phase ones. For pearlitic steel $(\alpha+\theta)$, when it suffers heavy plastic deformation, most dislocation burgeons at ferrite/cementite interfaces. This can be attributed to the strain incompatibility between soft phase $(\alpha)$ and hard phase $(\theta)$ [17]. Second, when particles (like carbides) have been distributed on ferrite matrix, it will accelerate the proliferation of dislocations by triggering the formation of secondary dislocations [22]. Therefore, it is reasonable to suggest that the combination of multiphase and particles in materials will improve the efficiency to turn more LAGBs to HAGBs during cold rolling.

In the present study, the initial microstructure with the combination of pearlite and granular carbides was obtained after isothermal heat treatment. The cold rolling process with the strain of 0.6 and 1.4 (40\% and 70\% rolling reduction) [19] has been conducted, respectively. The characterization on the evolution of the microscopic structure and dislocation near granular carbides in ferrite lamella has been investigated.

\section{Materials and Methods}

\subsection{Materials}

Experiments were conducted on a steel with a composition of $\mathrm{Fe}-0.69 \mathrm{C}-1.0 \mathrm{Si}-0.72 \mathrm{Mn}-2.41 \mathrm{Cr}-1.45 \mathrm{Ni}-0.61 \mathrm{Mo}$ wt $\%$. The process of austenite-pearlite transformation was performed on laboratorial muffle furnace before cold rolling.
The heat treatment is designed referring to phase profile with temperature of the experimental steel in equilibrium condition calculated by JMat-Pro V8 software as shown in Fig. 1a. Rectangular steel plates with thickness of $6 \mathrm{~mm}$ were austenitized at $860^{\circ} \mathrm{C}$ for $2 \mathrm{~h}$ followed by isothermal transformation at $680^{\circ} \mathrm{C}$ for $8 \mathrm{~h}$ and subsequently furnace cooling. Grinding machine was utilized to remove the surrounding oxide layer of steel plates with $5 \mathrm{~mm}$ left in thickness direction. Pearlitic steel plates (P0) were subjected to accumulated cold rolling with reduction ratios of $40 \%$ (CR4) and $70 \%$ (CR7) in three and eight passes. These deformation degrees correspond to equivalent strains $(\varepsilon)$ of 0.6 and 1.4 , respectively. Rolling deformation each pass (RDEP) of CR4 steel is $20 \%, 15 \%$ and $12 \%$. The RDEP of CR7 steel is $20 \%, 15 \%, 12 \%, 13 \%, 12 \%, 13 \%, 13 \%$ and $13 \%$. The corresponding heat treatment procedure and rolling process are shown in Fig. 1b.

\subsection{Mechanical Property Tests and Microstructure Characterization}

The microstructures and crystallographic features of coldrolled pearlitic steel plate were observed by scanning electron microscopy (SEM, JSM-7800F), transmission electron microscopy (TEM, JEM-2100F) and electron back-scattered diffraction (EBSD, MIRA3). All samples were cut from the center of cold-rolled steel plate. The SEM samples were polished carefully with $3 \mu \mathrm{m}$ brightener ending and etched using $4 \%$ nital solution. TEM samples were mechanically polished to $40 \mu \mathrm{m}$ along thickness direction and twin-jet electro-polished using the electrolyte mixing 5\% perchloric acid and $95 \%$ ethanol solution at $-28{ }^{\circ} \mathrm{C}$ with an applied current of $20 \mathrm{~mA}$. EBSD samples have experienced mechanical polishing and vibratory polishing elaboratively. The orientation maps were scanned from the surface perpendicular
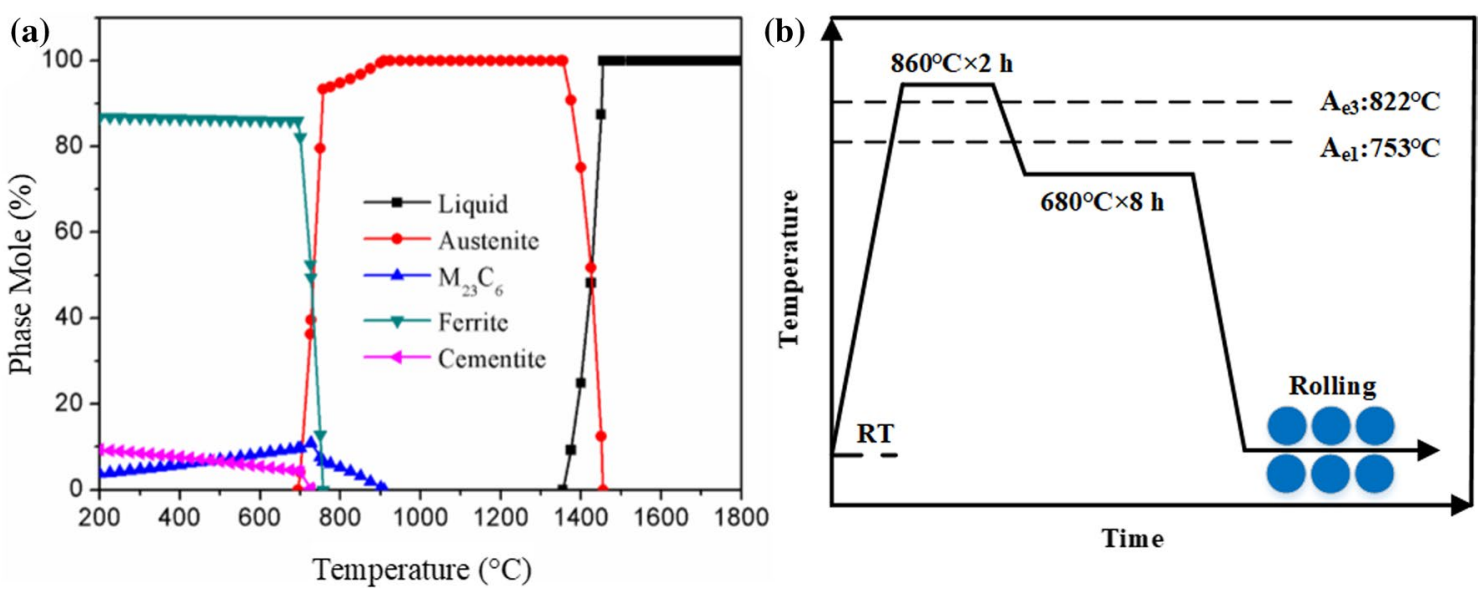

Fig. 1 Phase profile with temperature of the experimental steel (carbon content: 0.69 wt $\%$ ) in equilibrium condition calculated by JMat-Pro V8 software a, corresponding heat treatment and rolling process $\mathbf{b}$ 
to transverse direction at a step size of $50 \mathrm{~nm}$ from a square area of $15 \times 15 \mu \mathrm{m}$ in cold-rolled steel and a step size of $500 \mathrm{~nm}$ from a square area of $100 \times 100 \mu \mathrm{m}$ in initial pearlitic steel, respectively.

Tensile testing was performed on Zwick/Roell-Z100 tensile testing machine at room temperature. The overall length of tensile specimen is $43 \mathrm{~mm}$ with parallel length and width $15 \times 2 \mathrm{~mm}$. Dog-bone tensile samples were cut out in the center of the rolled steel plate along the RD direction. All tensile samples were subjected to uniaxial tension with a strain rate of $5 \times 10^{-4} / \mathrm{s}$.

\section{Results and Discussion}

\subsection{Microstructure Features of Pearlitic Steel After Cold Rolling}

In the initial as-heat-treated condition, the prior austenite grain size in the pearlitic steel is larger than $30 \mu \mathrm{m}$ as shown in Fig. 2a. Within prior austenite grain boundaries (PAGBs) (yellow lines) and nodules boundaries (blue lines), some pearlite colonies with no preferred microscopic orientation have the size in lengthwise and width directions are about 25 and $10 \mu \mathrm{m}$, respectively. In pearlitic colonies, granular carbides are embedded between lamellar cementites (Fig. 2b). This morphology is attributed to the designed heat process used in the present research. In the expected carbidesembedded structure, the grain size of carbides ranges from 100 to $500 \mathrm{~nm}$ (Fig. 2c). The measurements of carbides size from the longitudinal and transverse sections are in a little difference.

At the strain of 0.6, PAGBs tended to get stretched. At this strain, the cementite lamellas have begun to rotate toward the rolling direction (RD). When twisted into rolling direction, bent cementite lamellas are observed in Fig. 2d. In some colonies, the angle of bending can reach $63.5^{\circ}$ (Fig. 2f). The twisting is severe and fracture of cementite lamellas takes place, especially in the area where granular carbides exist (Fig. 2e, f). At the strain of 1.4, almost all of cementite lamellas within different colonies have rotated to rolling direction and have been elongated (Fig. $2 \mathrm{~g}$ ). The diversity in crystallographic orientation of colony has resulted in two types deformed structures in CR7 after rolling (Fig. 2h, local enlargement of Fig. 2g). The twisting of cementite is severe, and some colonies are much thinner compared with those at strain of 0.6. In some locations, fine lamellar area can be clearly observed. On the other hand, the degree of fracture
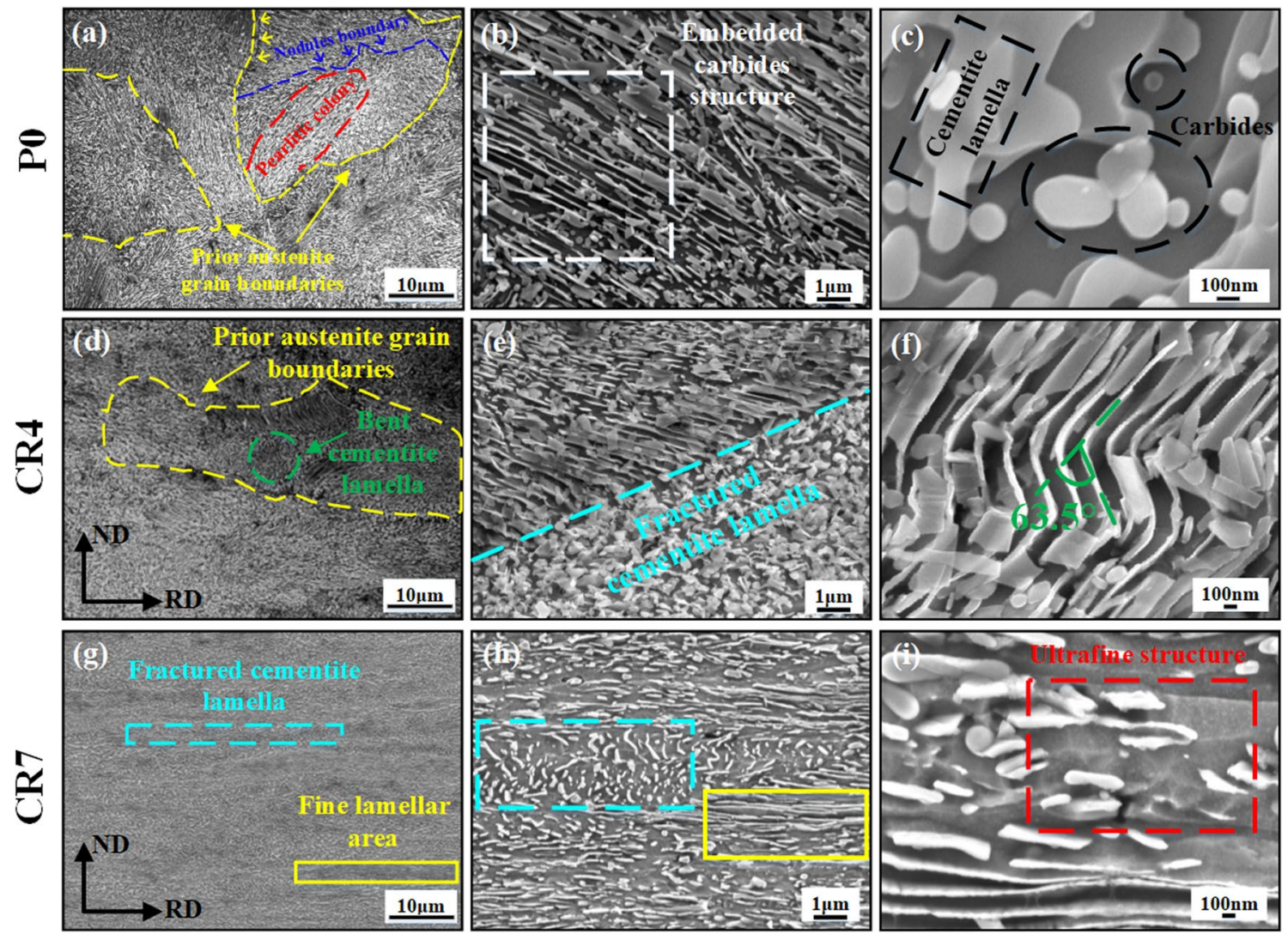

Fig. 2 Different magnification SEM images of pearlitic steel cold rolled to strain of $\varepsilon=0 \mathbf{a}, \mathbf{b}, \mathbf{c}, \varepsilon=0.6 \mathbf{d}, \mathbf{e}, \mathbf{f}, \varepsilon=1.4 \mathbf{g}, \mathbf{h}, \mathbf{i}$ 
in lamellar cementite is further deepened. The evolution of a microstructure where the pearlitic colony structure is repeatedly folded along an axis parallel to the rolling direction resulting in an ultrafine structure is shown in Fig. 2i. These figures clearly show that the pearlitic colony and cementite lamellas are rotated toward the rolling axis with increasing strain and elongated along the rolling direction. During twisting process, many cementite plates fracture or become thinner and the microstructure is noticeably refined with increasing imposed strain. The presence of granular carbides has an important effect on microstructure evolution.

The characteristics of these carbides in this steel are illustrated in Fig. 3. From Fig. 3a, b, it can be seen that some $M_{3} \mathrm{C}$ with small grain size $(50-200 \mathrm{~nm})$ generate from the degeneration of pearlite (DP) at subsequent long-time isothermal transformation and furnace cooling. The similarsized $M_{23} \mathrm{C}_{6}$ is also obtained after heat treatment which is shown in Fig. 3c, d. From energy-dispersive X-ray spectroscopy (EDX) elemental mapping images, a higher chromium concentration exists in the granular carbides $M_{3} \mathrm{C}$ not the cementite lamella. This suggests that the microhardness of granular carbides $M_{3} \mathrm{C}$ is also higher. The morphologies illustrated in Fig. $3 \mathrm{e}$, f show that carbides $M_{3} \mathrm{C}$ and $M_{23} \mathrm{C}_{6}$ may distribute in adjacent positions. This phenomenon shows that these two kinds of carbides will have the cooperative relationship on affecting the microstructure change during cold rolling.

\subsection{Granular Carbides-Assisted Grain Refinement in Pearlitic Steel During Cold Rolling}

Figure 4 shows the combined maps of rolling-direction inverse pole figure (RD-IPF), boundary maps, band contrast (BC) and kernel average misorientation (KAM) which are obtained from P0, CR4 and CR7 steels. The IPF colored maps of unstrained and strained samples in Fig. 4a, c, g show that the pearlitic colony has been elongated dramatically after cold rolling along RD. At the strain of 0.6 , there exist many LAGBs in ferrite matrix but almost no ultrafine grains can be found (Fig. 4d). When increasing strains, the microstructure of colony was intensely refined as shown in Fig. 4e, f. It is not difficult to find the tendency that more HAGBs of bcc (black lines) often accompany with granular carbides (GCs) (outlined in green color) appearance. The corresponding distributions of grain size and grain boundary are illustrated in Fig. 5. The average grain sizes of ferrites in P0, CR4 and CR7 steels are $15.86 \mu \mathrm{m}, 4.56 \mu \mathrm{m}$ and $0.65 \mu \mathrm{m}$ with the type of area averaging, respectively (Fig. 5a). As shown in Fig. 5b, the fraction of LAGBs in CR4 steel is about $91 \%$ which is much higher than that of in CR7 steels with $64.2 \%$. The misorientation angles of HAGBs in CR7 steel majorly fall in the range of $15^{\circ}$ to $35^{\circ}$.

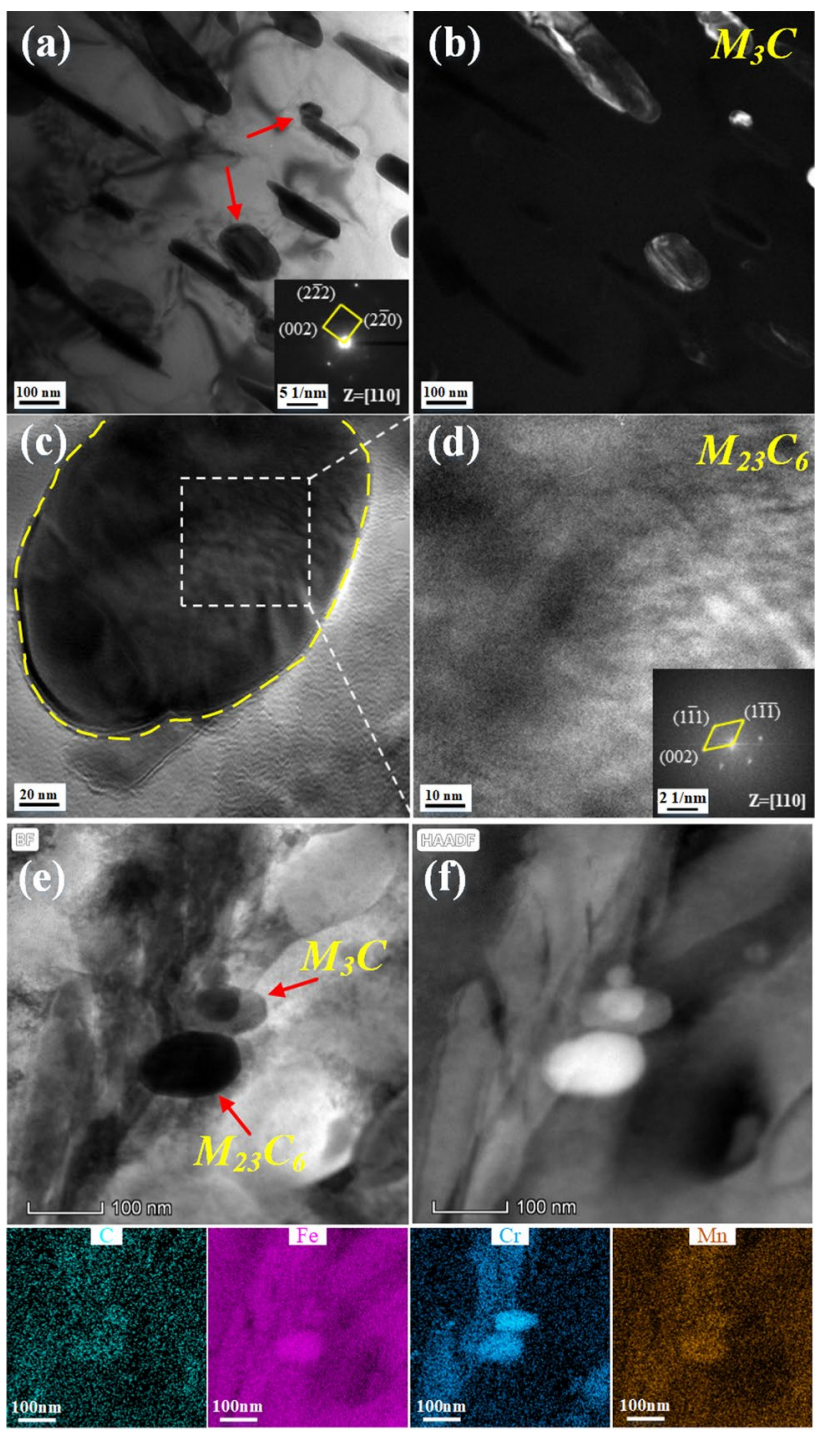

Fig. 3 TEM images of carbides in P0: a degenerated lamellar cementite and granular $M_{3} \mathrm{C}$ with inserted diffraction pattern after heat treatment process, $\mathbf{b}$ dark field of $M_{3} \mathrm{C}, \mathbf{c}$ and $\mathbf{d}$ high-resolution transmission electron microscopy (HRTEM) images of $M_{23} \mathrm{C}_{6}$ and its corresponding fast Fourier transform (FFT) patterns on lower right corner, e bright field (BF) of scanning transmission electron microscopy (STEM) micrograph, f high-angle annular dark-field (HAADF) image and EDX elemental mappings of $\mathrm{Fe}$ and $\mathrm{Cr}$ elements below

In these figures, refined ferrite along rolling direction in the steel deformed with the strain 1.4 is indicated. These observations show that the change in the morphology of ferrite phase is heterogeneous even in same pearlitic colony. Generally, the local constraint in ferrite can be divided into two parts. One comes from the imposed strain through the cold rolling. Other one derives from the localized resistance based on the distribution of granular carbides. These results suggest that the deformation behavior of ferrite is closely related to the embedded carbides. Then, two equalarea subsets with identical crystallographic orientation are 
selected from one colony for analyzing the effect of carbides on ferrite refinement. In the same colony, the influence rules of granular carbides on grain refinement can be studied precisely by using this variable-controlling approach. This is based on the following considerations: (i) pearlitic colony has extremely similar crystallographic orientation distinguished from the adjacent colonies [23]. The stress distribution varies in different colonies, along with the $\theta$ phase. Although the volume fraction of cementite is far less than that of ferrite, the plastic deformation and flow stress of pearlitic steels are profoundly dominated by its existence [24]; (ii) cold rolling has brought gradient variation of microstructure derived from the diverse strain and strain rate by its complex local stress distribution [25].

As shown in Fig. 4f-h, the subset with more GCs (8.7\%, vol.\%) is framed in black dotted line (enlarged in S1), while other one (4\% GCs, vol.\%) is outlined in red dotted line (enlarged in S2). Then, the distribution curves of grain size, grain boundary and local misorientation in whole area (only ferrite included, all) and local regions (subset 1, subset 2) of CR7 steel are illustrated in Fig. 6. These comparisons may provide a quantitative evaluation on grain refinement. It is noteworthy that the fractions of ultrafine ferrite $(<1 \mu \mathrm{m})$ in whole area and subset 1 are very high. As listed in Table 1, the average grain size (HAGBs) of subset 1 and subset 2 is $388 \mathrm{~nm}$ and $810 \mathrm{~nm}$, respectively, with the type of area averaging (all is $651 \mathrm{~nm}$ ). Then, the average subgrain size (LAGBs) of subset 1 is $167 \mathrm{~nm}$, which is also smaller than $201 \mathrm{~nm}$ of subset 2 . So, The carbides-assisted grain refinement during cold rolling with low equivalent strain is quite obvious.

From the grain boundary distribution figure, the fraction of HAGBs $\left(2^{\circ}<\theta \leq 15^{\circ}\right)$ in subset 1 is $53.8 \%$, while that of subset 2 is $35.8 \%$. In Fig. 6c, comparing subset 1 with subset 2, the peak width of local misorientation distributions becomes broader and its peaks have a tendency to shift toward higher misorientation angles. This result indicates that the development on intragranular misorientation of subset 2 is higher than that of subset 1, although both subsets suffer identically imposed strain. To further compare the dislocation states between colonies with different carbide volume fractions, the stored energy which is mainly attributed to the generation of geometrically necessary dislocations (GNDs) can be calculated by the following formula. The formula includes five respective parameters: average local misorientation ( $\theta$ in radians), a constant $\alpha$ which is connected with geometry of grain boundary (their values are 2,4,3 for pure tilt boundaries, twist boundaries and mixed boundaries, respectively), shear modulus $(G)$, step size $(d)$ for EBSD analysis and burgers vector $(b)$ [26].

$E=\frac{\alpha \theta G b}{2 d}$.
In the present research, the values of $\theta_{1}$ and $\theta_{2}$ are 0.0328 $\left(1.88^{\circ}\right)$ and $0.029\left(1.66^{\circ}\right)$, respectively. LAGBs is deemed to have mixed boundaries, so the constant $\alpha$ is decided to be 3 . The step size $d$ is $50 \mathrm{~nm}$. Shear modulus $G$ of carbon steel approximately is $77.5 \mathrm{GPa}$, and burgers vector is $0.248 \mathrm{~nm}$ [24]. Therefore, stored energies in these two deformed regions are $135 \mathrm{~J} / \mathrm{mol}$ and $119 \mathrm{~J} / \mathrm{mol}$, respectively. Assuming the preexisting stored energy per unit volume in the same colony of undeformed pearlite is identical, the finally stored energy in subset 1 is higher than that of subset 2 during rolling process. Consequently, the combination of these results indicates that after cold rolling the region which owns more GCs always has higher dislocation density and more stored energy to generate fresh ultrafine ferrite grains.

As shown in Fig. 7a, b, the undeformed pearlitic colony is characterized by well-aligned cementite and ferrite lamellar with pretty low dislocation density. Its interlamellar spacing (ILS) is about $358 \mathrm{~nm}$. GCs and degenerated lamellar cementite (DLC) are visible as well. In order to verify where and how the local dislocations are generated and accumulated, Fig. 7c-e shows the morphology of deformed colony in intermediate rolling stage with $40 \%$ rolling reduction. With increasing imposed strains, the fracture of cementite lamellas is obtained and a large number of dislocations are generated in the interface between ferrite and cementite and interior of ferrite, especially in the region where granular carbide exists. Dislocation movements are also blocked by neighboring carbides, and then high-density heavily tangled dislocations or cells are formed.

Continuing to increase strain to 1.4 , more dislocations will be nucleated and trapped by the dense dislocation boundaries (DDBs) or dislocation cell walls (Fig. 8). The dislocation interaction will become more active. Sharpened DDBs will be gradually rearranged and evolved into LAGBs or HAGBs in the lamellar ferrite to lower the Gibbs free energy $[9,17,18]$. Thus, as shown in Fig. 8b-d, ultrafine ferrite grains adjoining GCs will be generated. From the darkfield image and inset diffraction pattern, it can be observed that many ultrafine ferrite grains exist in this visual filed and one of them shown in Fig. $8 \mathrm{c}$ is about $278 \mathrm{~nm}$. The observations in Fig. 8e-h show that the increase in dislocation density not only depends on volume fraction of carbides but also on the shape of carbides. Dislocations (as shown by the yellow arrow) taking place near elliptic carbides and resulting from cold rolling are more frequently observed than that of linear carbides. The generation of these linear carbides may be from degenerated lamellar cementite before rolling process or fractured short cementite lamellas after cold rolling.

Generally, in common pearlitic colony without embedded granular carbides, it is almost impossible to obtain so many fractured cementite lamellas and fresh ultrafine ferrites with so low-strain cold deformation [25, 27, 28]. In Ref. [25], when pearlite specimen was rolled by $70 \%$, the bent lamella 

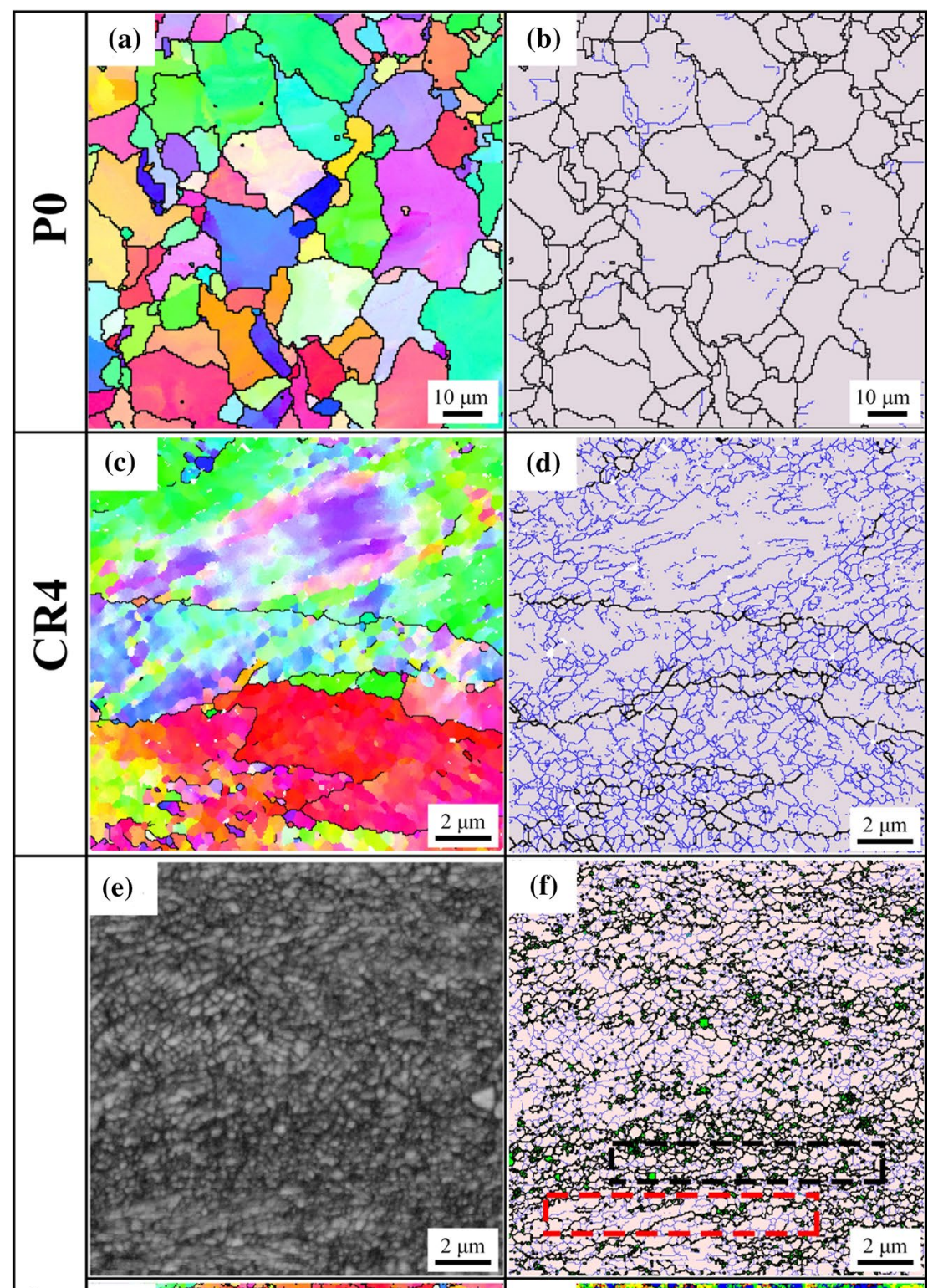

v

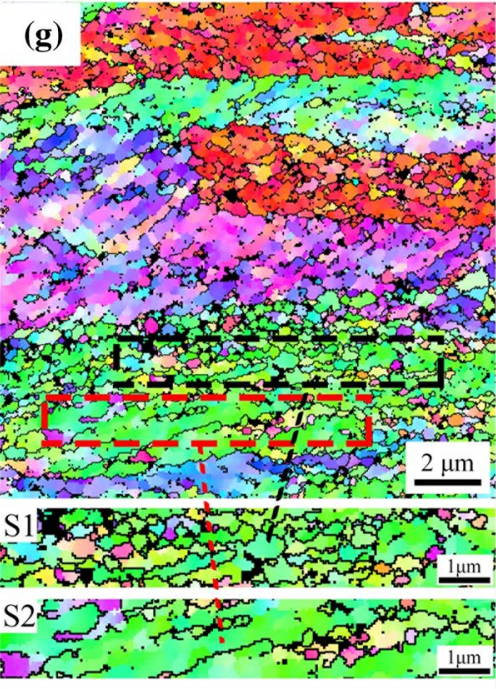

(h)
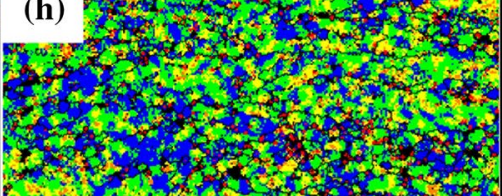

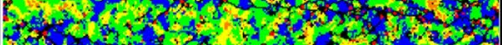

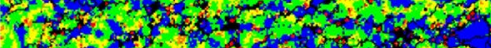

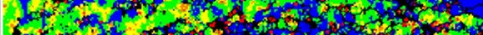

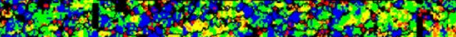
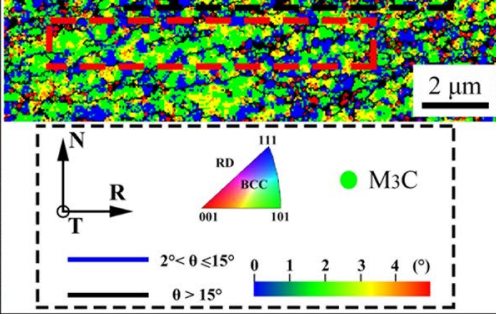
4Fig. 4 Combined maps of RD-IPF, boundary maps, band contrast and KAM obtained from P0 a, b, CR4 c, d, CR7 steels e-h; S1: subset with more GCs which is framed in black dotted line, S2: subset with few GCs which is framed in red dotted line

cementite is the majority structure and fine lamella cannot be clearly observed. In Ref. [28], the microstructure was gradually refined with an increase in the rolling strain. The ILS of pearlite decreased and no fractured cementite lamella showed. Thus, it can be seen that the introduction of carbides had a great effect on the changes in the microscopic structure and the evolution of dislocation near granular carbides in ferrite lamella of pearlitic colony.

From these observations in EBSD and TEM images, corresponding evolution of microstructure in pearlitic colony during cold rolling can be assumed and instantiated in Fig. 9. First, most of the dislocations will be nucleated at the interfaces of $\alpha / \theta$ and $\alpha / \mathrm{GCs}$ [22]. At larger plastic strains, the dislocation density increases and dislocation motions will be blocked by neighboring lamellar cementite. As the dislocation reactions like jogging or tangling happen, the dense dislocation boundaries will develop in ferrite as lowangle grain boundaries [17]. On the other hand, when the concentration of stress in local area is severe, the fracture of lamellar cementite during cold rolling will provide fresh granular cementite (GC-2) to accelerate the dislocation reactions. Finally, these intersection DDBs will introduce more misorientation and subdivide the large grains into smaller ones in which new HAGBs will be generated. From TEM images in Fig. 7, it can be concluded that there exist two kinds of subdivision modes which resulted in grain size with the heterogeneous distribution.

As shown in Fig. 10, the first mode (M1) is mainly caused by the carbides $\left(M_{23} \mathrm{C}_{6}\right.$ or fractured lamellar $\left.\theta\right)$ which exists in the position between two cementite lamellas. Then, the grain size of ferrite ranges from the value of half ILS to one ILS. The other mode (M2) is attributed to the granular cementite from DP. These granular carbides will take the place of previous lamellar cementite. The incoherent $\alpha / \mathrm{GCs}$ structure offers lots of nucleation sites for dislocations. It is reasonable to infer that the minimal grain size on M2 might be the value of one ILS. It is noted that the whole refinement process is complicated which might be attributed to the interaction between these two modes. Whatever the subdivision mode is, the existence of GCs in ferrite matrix will accelerate the evolution of dislocation propagation, entanglement, annihilation and fresh ultrafine ferrites are obtained finally. The more the GCs, the more the ultrafine ferrite grains. As discussed above, there exist two types of carbides, $M_{3} \mathrm{C}$ and $M_{23} \mathrm{C}_{6}$, with grain size about $100 \mathrm{~nm}$ in the matrix. The presence of all these particles is beneficial to the grain refinement process by enhancement in the development of the dislocation structure. Because the secondary slip of dislocation will happen near these carbides. These secondary dislocations either fill in these positions between the carbides and then are arranged into dislocation walls [22], or spread away through Orowan dislocation bypassing or dislocation shearing mechanisms [29, 30].

Generally, the detailed interactions of the carbides with dislocations are also controlled by the distribution and grain size of these particles [31, 32]. For small-size carbides, the cementite $\left(M_{3} \mathrm{C}\right)$ particle is incoherent with the bcc matrix, so the Orowan dislocation bypassing mechanism is dominant in the dislocation interaction, especially when the size becomes very small [30]. In the steel with $M_{23} \mathrm{C}_{6}$ carbide, the dislocations usually bypass the carbide and then leave loops surrounding them, so Orowan dislocation bypassing mechanism is always dominant in this system [33]. For big-size carbides, these dislocations are scarcely possible to bypass and thus blocked in front of these obstacles [34]. Finally, these carbides will significantly increase the intragranular dislocation density considering the limited dislocation movement near these carbides. In the present research, most carbides $\left(M_{3} \mathrm{C}\right.$ and $\left.M_{23} \mathrm{C}_{6}\right)$ distributing in ferrite have a big size (>100 nm), so dislocations are hard to bypass and thus tangled around the carbides. Finally, these highdensity dislocations will generate into low-energy dislocation walls. Moreover, considering extremely small carbides may exist in the matrix, the Orowan dislocation bypassing mechanism will also affect the dislocation interaction with these carbides.

\subsection{Mechanical Property of Pearlitic Steel After Cold Rolling}

Boundary strengthening $\left(\sigma_{\mathrm{b}}\right)$ mechanism is vital for analyzing the relationship between microstructure and strength in pearlitic steel. For ordinary pearlitic steel with lamellar ferrite and cementite, $\sigma_{\mathrm{b}}$ can be calculated based on the Hall-Petch equation and the barrier distance (equivalent to the value of grain size) is estimated to be twice the ferrite lamellae ( $d$, approximately equal to ILS) [35], that is:

$\sigma_{\mathrm{b}}=\sigma_{0}+k_{\mathrm{y}}(2 d)^{-1 / 2}$.

Equation (2) is also applied to the present research. The fresh ultrafine ferrites emerging in former lamellar structure position after suffering imposed strain will change the selection of parameter, barrier distance. It is not difficult to find that the barrier distance as core parameter will be substituted by grain size. That is, the barrier distance will be shortened to the value of one ILS or less in other words. Therefore, the contribution of boundary strengthening in yield strength is higher in the present designed microstructure than the common deformed pearlitic steel. 

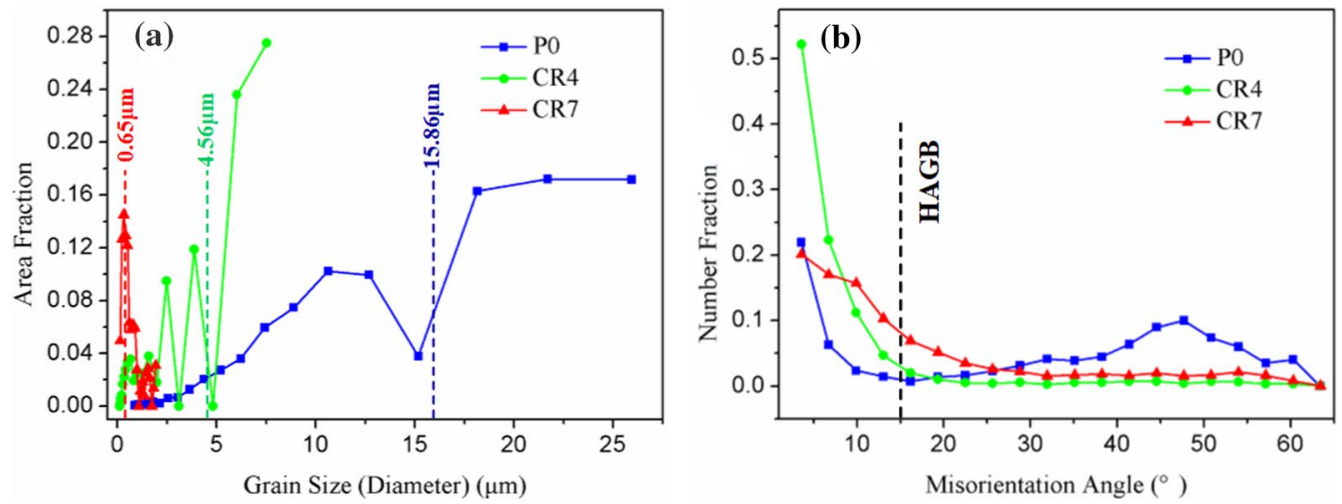

Fig. 5 Comparison between P0, CR4 and CR7 steel involving in grain size distribution a, grain boundary distribution b
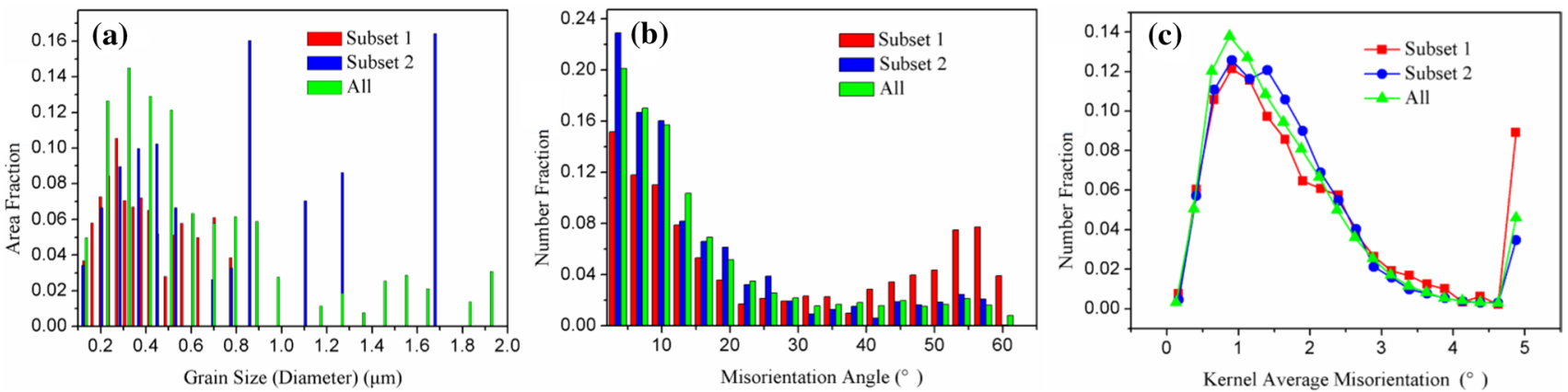

Fig. 6 Comparison between whole area and local regions (subset 1, subset 2) of CR7 steel involving in grain size distribution a, grain boundary distribution b, KAM c

Table 1 Average values of the microstructural parameters for three different regions in CR7 steel

\begin{tabular}{|c|c|c|c|c|c|c|}
\hline \multirow[t]{2}{*}{ Regions } & \multicolumn{3}{|c|}{ LAGBs (\%) } & \multirow{2}{*}{$\begin{array}{l}\text { HAGBs (\%) } \\
15^{\circ}-180^{\circ}\end{array}$} & \multicolumn{2}{|c|}{ Grain size $(\mathrm{nm})$} \\
\hline & $2^{\circ}-5^{\circ}$ & $5^{\circ}-10^{\circ}$ & $10^{\circ}-15^{\circ}$ & & Subgrain & Grain \\
\hline Subset 1 & 14.6 & 18.6 & 13 & 53.8 & 167 & 388 \\
\hline Subset 2 & 22.4 & 27 & 14.9 & 35.8 & 201 & 810 \\
\hline All & 19.4 & 26.6 & 18.2 & 35.8 & 120 & 651 \\
\hline
\end{tabular}

As shown in Fig. 11 and Table 2, the yield strength (YS) of pearlitic steel increases from 474 to $1253 \mathrm{MPa}$ after being subjected to $70 \%$ cold rolling process. In the middle stage at the strain 0.6 , the strength improvement of materials is not very obvious. On the contrary, the reduction in ductility is arresting. When the imposed strain increases to 1.4 , the ultimate tensile strength (UTS) has a dramatic increase with $432 \mathrm{MPa}$. Grain refinement and high-density dislocations make a great contribution to the enhancement of strength. It is surprising that the total elongation (TE) also has an increment. Ultrafine-grained (UFG) materials produced by the severe plastic deformation are generally characterized with high strength and insufficient ductility which is derived from the limited dislocation movement [36]. Therefore, in order to enhance the dislocation activity in these UFG materials, various methods can be conducted, like producing the materials with bimodal structure [37], nanoscale precipitates [38], twin boundaries [39], and so on. However, none of these elements exists in the present microstructure for further analysis. The lamellar structure with large amounts of subgrains or low-angle grain boundaries can also lead to enhancement of ductility in UFG materials. In tensile deformation process, the dislocation will glide through these small barrier (LAGBs) based on its low misfit angle. Continuous slip will occur within the lamellar structure, which will lead to the accumulation of dislocations [40].

From Sect. 3.2, it has already been known that highdensity dislocation exists in deformed pearlitic steel. As the dislocation reactions intensified with the increased strain, the microstructure was extremely refined via the assistance of granular carbides and many subgrains will generate in ferrite matrix. Therefore, sufficient and higher ductility in 

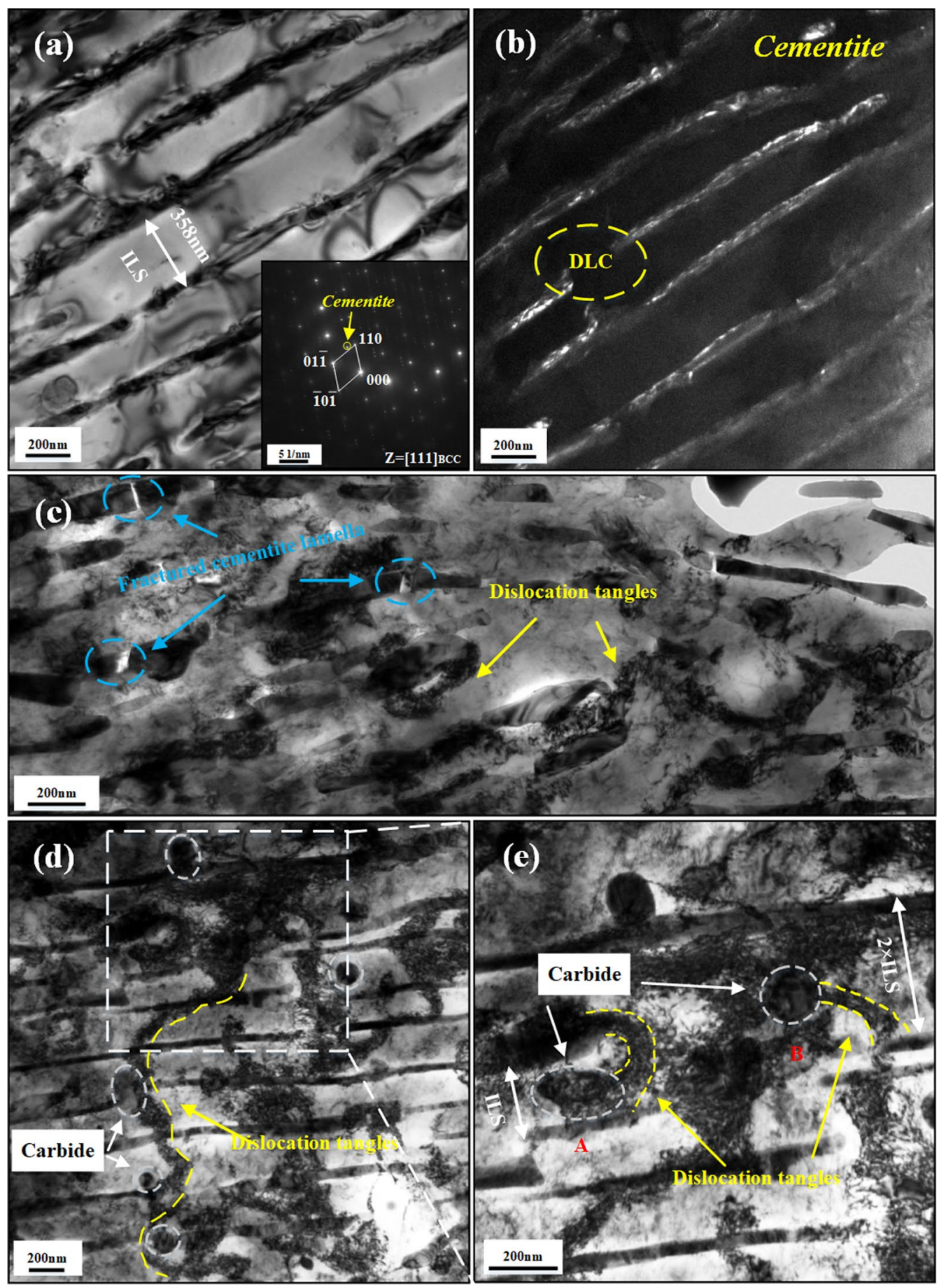

Fig. 7 Typical TEM images and corresponding selected area electron diffraction (SAED) patterns of P0 a, b; CR4 c-e

the CR7 steel can be attributed to extremely refined microstructure and plenty of subgrains existing in matrix after plastic deformation. Plastic instability which is often found in tensile test of ultrafine materials can also be observed in CR7 steel (black dotted line). For UFG materials, due to the relenting dislocation motions during uniaxial tension, dislocation-accumulation ability will lose and strain hardening ability is also low [36]. For high-strength ultrafine-grained CR7 steel and CR4 steel, other strengthening mechanisms such as solid solution hardening and second-phase strengthening also have much impacts on its strength. 

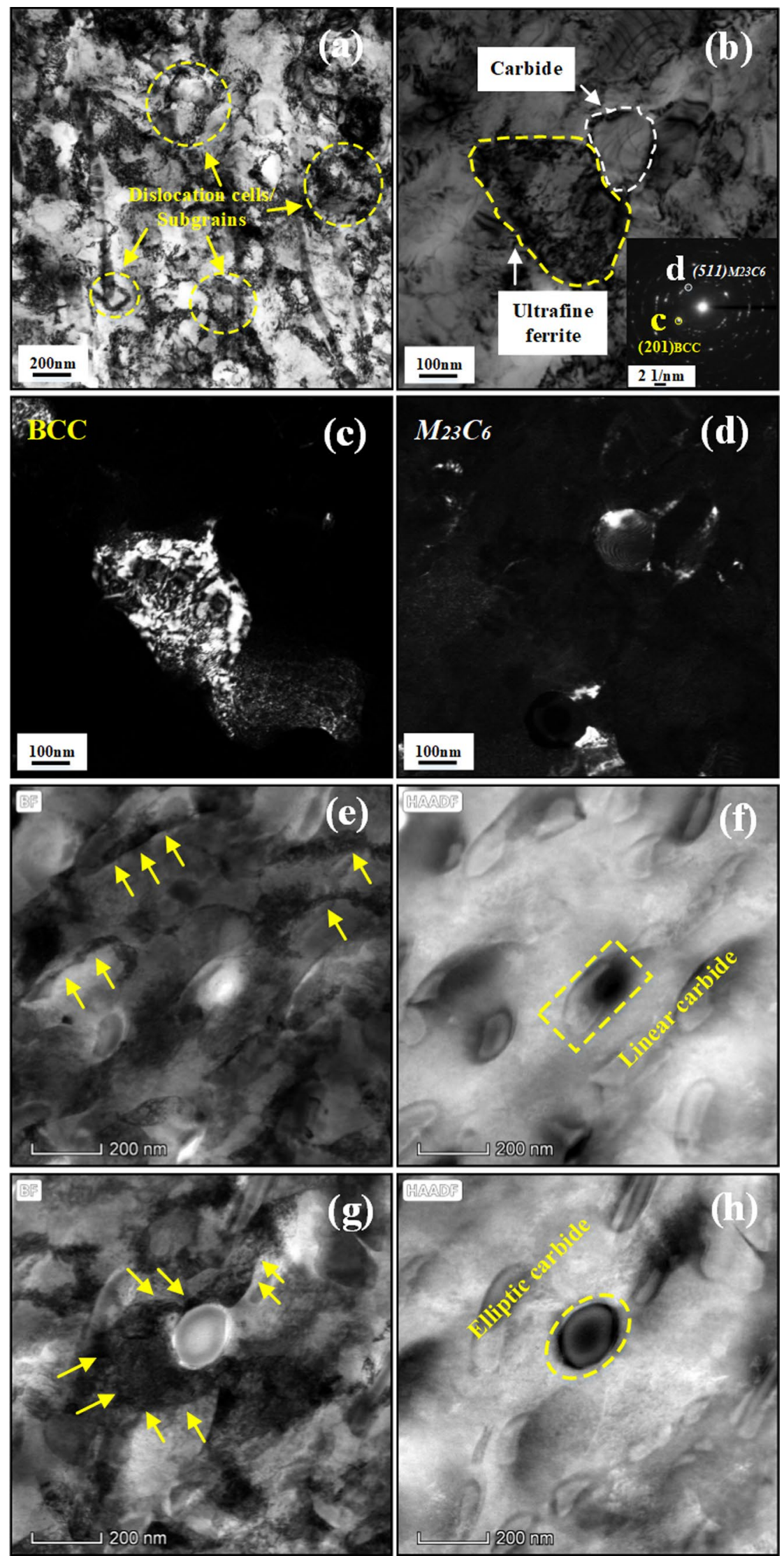
४Fig. 8 Typical TEM images, corresponding SAED patterns and STEM images of CR7 steel: a ultrafine structures generated after cold rolling, b bright field (BF) of ultrafine ferrite accompanied by granular carbide and corresponding SAED patterns, c, d dark field of ultrafine ferrite and $M_{23} \mathrm{C}_{6}$, e, f BF and HAADF images of the deformed structure with linear carbide, $\mathbf{g}, \mathbf{h}$ BF and HAADF images of the deformed structure with elliptic carbide

\section{Conclusions}

In the present study, evolution of cementite lamella and ferrite grain during cold rolling in a granular car- cold deformation. Large amounts of fractured cementite lamella were obtained in CR4 steel $(\varepsilon=0.6)$, and much fine lamellar structure was generated in CR7 steel $(\varepsilon=1.4)$.

2. Ultrafine ferrite $(\sim 388 \mathrm{~nm})$ can be fabricated through low equivalent strain $(\varepsilon=1.4)$ cold rolling without SPD. Formation of these UFG is closely associated with the presence of granular carbides. The average grain size of ferrite depends on the volume fraction, shape, distribution of granular carbides and interlamellar spacing of pearlite. A general explanation of granular carbides-
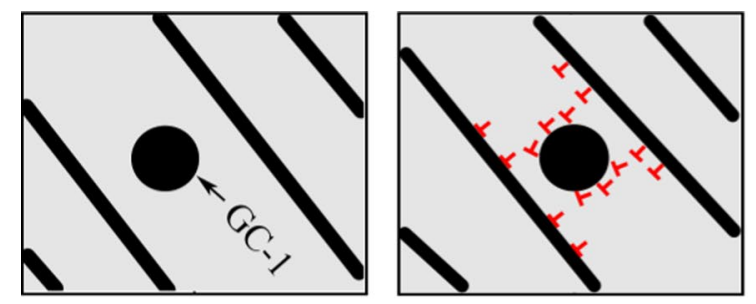

Stage 1
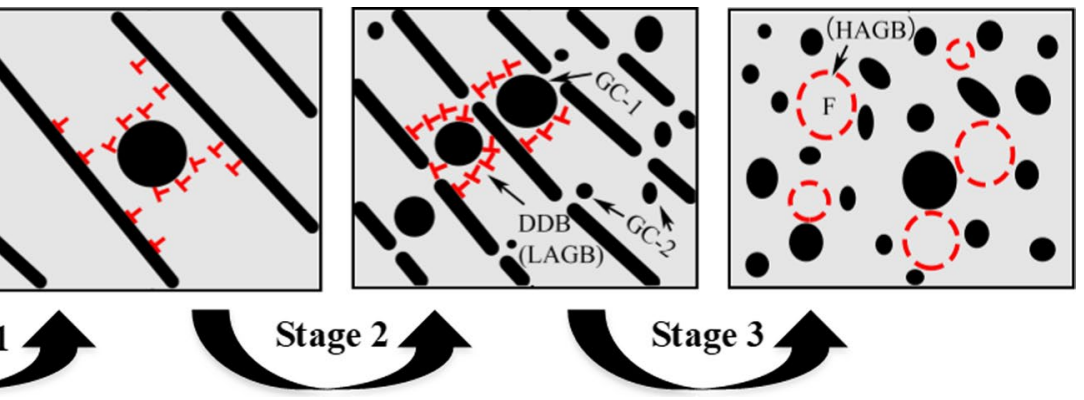

Fig. 9 Schematic diagram of ultrafine ferrite generated in pearlitic colony during cold rolling

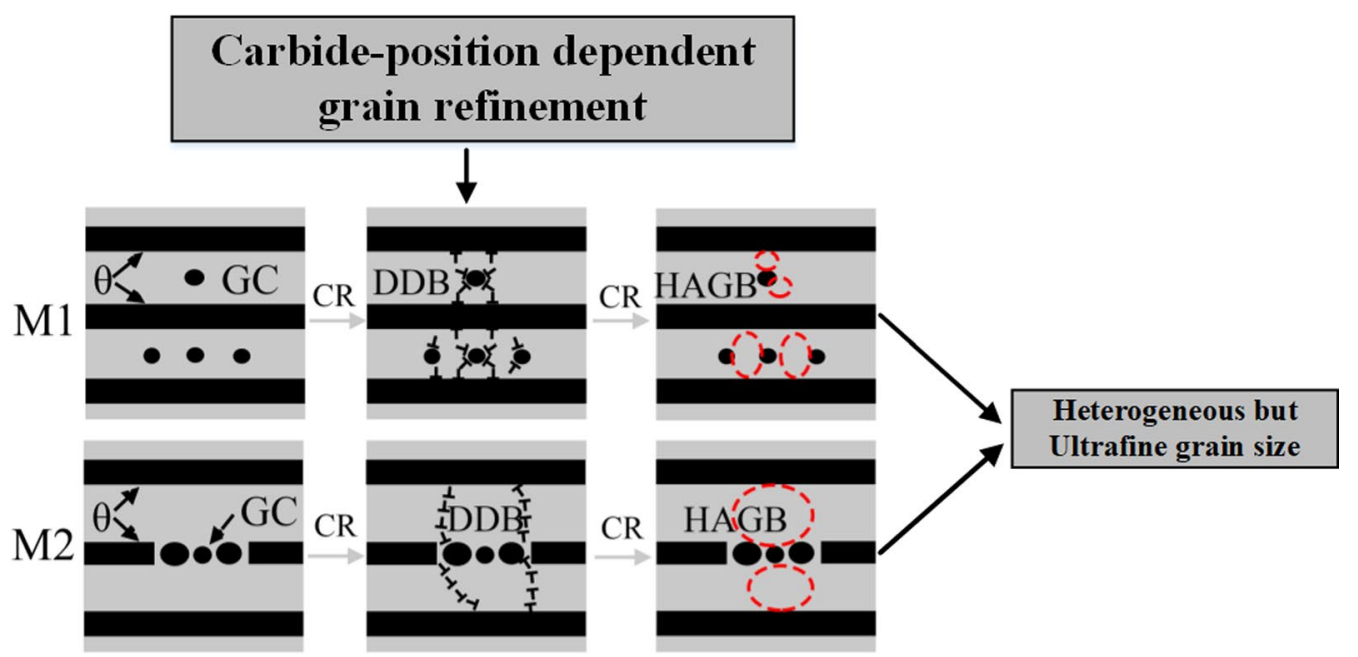

Fig. 10 Schematic diagram of two refinement modes of ferrite in pearlitic colony during cold rolling

bide-pearlite steel has been investigated by SEM, TEM, EBSD under low equivalent imposed strain. The effect of microstructure on the tensile strength was also analyzed. The following conclusions can be drawn:

1. The presence of granular carbides had a great effect on the microstructural evolution of pearlitic colony during assisted grain refinement is that embedded carbides between natural barrier will significantly facilitate dislocation nucleation during deformation.

3. The formation of ultrafine ferrite grains and subgrains in steel after cold rolling to $\varepsilon=1.4$ strain makes the 


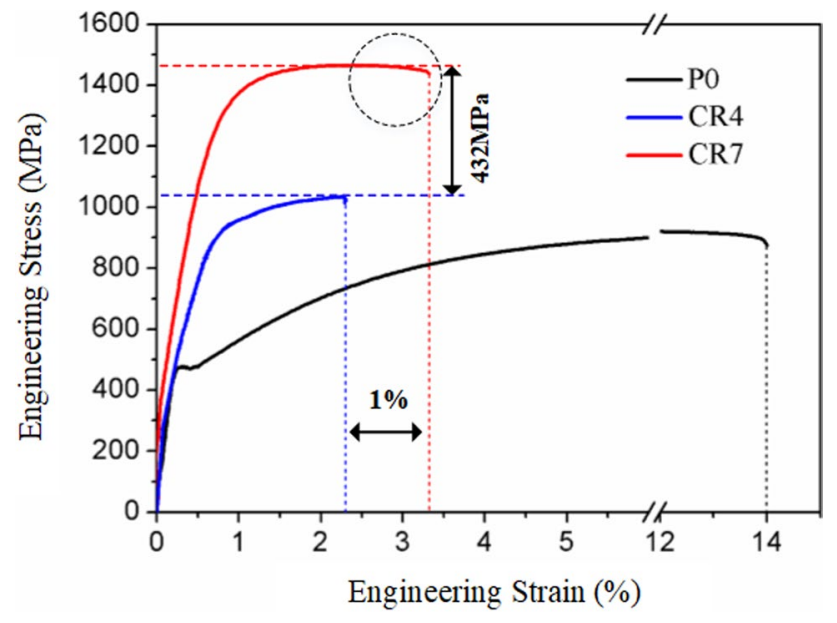

Fig. 11 Engineering stress-strain curves of P0, CR4 and CR7 steels

Table 2 Calculated and summarized values of well-assorted mechanical properties from $\mathrm{P} 0, \mathrm{CR} 4$ and $\mathrm{CR} 7$ steels

\begin{tabular}{lccr}
\hline Samples & YS (MPa) & UTS (MPa) & \multicolumn{1}{c}{ TE $(\%)$} \\
\hline P0 & $474 \pm 4$ & $923 \pm 3$ & $13.9 \pm 0.9$ \\
CR4 & $775 \pm 5$ & $1033 \pm 8$ & $2.3 \pm 0.2$ \\
CR7 & $1253 \pm 11$ & $1465 \pm 11$ & $3.3 \pm 0.3$ \\
\hline
\end{tabular}

strength and ductility increasing simultaneously compared with $\varepsilon=0.6$ cold-rolled steel.

Acknowledgements This work was supported by the Major Project for National Science and Technology of China (No. 2014ZX07214002) and the BAOSTEEL-SJTU Joint Research Center for Future Steel. The author (L. Fu) is grateful for the financial support from the Startup Fund for Youngman Research at SJTU (No. SJTU.18X100040023).

\section{References}

[1] Y. Li, D. Raabe, M. Herbig, P.P. Choi, S. Goto, A. Kostka, H. Yarita, C. Borchers, R. Kirchheim, Phys. Rev. Lett. 113, 106104 (2014)

[2] P.D. Hodgson, M.R. Hickson, R.K. Gibbs, Scr. Mater. 40, 1179 (1999)

[3] R. Ueji, N. Tsuji, Y. Minamino, Y. Koizumi, Acta Mater. 50, 4177 (2002)

[4] H.S. Dong, W.J. Kim, W.Y. Choo, Scr. Mater. 41, 259 (1999)
[5] J. Čížek, M. Janeček, T. Krajňák, J. Stráská, P. Hruška, J. Gubicza, H.S. Kim, Acta Mater. 105, 258 (2016)

[6] L. Lv, L. Fu, Y. Sun, A. Shan, Mater. Sci. Eng. A. 731, 369 (2018)

[7] C. Zheng, L. Li, W. Yang, Z. Sun, Mater. Sci. Eng. A. 558, 158 (2012)

[8] A. Momeni, S.M. Abbasi, J. Mater. Sci. Technol. 27, 338 (2011)

[9] S. Lu, Z. Wang, K. Lu, J. Mater. Sci. Technol. 26, 258 (2010)

[10] B. Hu, H. Luo, F. Yang, J. Mater. Sci. Technol. 33, 1457 (2017)

[11] A. Azushima, R. Kopp, A. Korhonen, D. Yang, F. Micari, G. Lahoti, P. Groche, J. Yanagimoto, N. Tsuji, A. Rosochowski, CIRP Ann. 57, 716 (2008)

[12] M. Furukawa, Z. Horita, M. Nemoto, T.G. Langdon, Mater. Sci. Eng. A 324, 82 (2002)

[13] T.G. Langdon, Mater. Sci. Eng. A 462, 3 (2007)

[14] A. Belyakov, K. Tsuzaki, H. Miura, T. Sakai, Acta Mater. 51, 847 (2003)

[15] Y. Ko, W. Jung, D. Shin, C. Lee, Scr. Mater. 48, 197 (2003)

[16] R. Saha, R. Ueji, N. Tsuji, Scr. Mater. 68, 813 (2013)

[17] L. Zhou, G. Liu, X.L. Ma, K. Lu, Acta Mater. 56, 78 (2008)

[18] R.Z. Valiev, R.K. Islamgaliev, I.V. Alexandrov, Prog. Mate. Sci. 45, 103 (2000)

[19] D. Hughes, N. Hansen, Acta Mater. 45, 3871 (1997)

[20] Y. Ivanisenko, W. Lojkowski, R. Valiev, H.J. Fecht, Acta Mater. 51, 5555 (2003)

[21] Y. Ivanisenko, R. Wunderlich, R. Valiev, H.J. Fecht, Scr. Mater. 49, 947 (2003)

[22] C.Y. Barlow, N. Hansen, Acta Mater. 37, 1313 (1989)

[23] J. Toribio, E. Ovejero, Scr. Mater. 39, 323 (1998)

[24] G. Langford, Metall. Trans. A 8, 861 (1977)

[25] S. Tagashira, K. Sakai, T. Furuhara, T. Maki, ISIJ Int. 40, 1149 (2000)

[26] Y. Takayama, J.A. Szpunar, Mater. Trans. 45, 2316 (2004)

[27] X. Zhang, A. Godfrey, N. Hansen, X. Huang, W. Liu, Q. Liu, Mater. Charact. 61, 65 (2010)

[28] Y. Liu, C.D. Yang, M. Liu, C.H. Wang, Y.C. Dai, X. Li, A.M. Russellc, C.X. Zhang, Z.H. Zhangd, G.H. Cao, Mater. Sci. Eng. A 709, 115 (2018)

[29] T. Gladman, Mater. Sci. Technol. 15, 30 (1999)

[30] J.S. Wang, M.D. Mulholland, G.B. Olson, D.N. Seidman, Acta Mater. 61, 4939 (2013)

[31] J. Fu, G. Li, X. Mao, K. Fang, Metall. Mater. Trans. A 42, 3797 (2011)

[32] K. Ma, H. Wen, T. Hu, T.D. Topping, D. Isheim, D.N. Seidman, E.J. Lavernia, J.M. Schoenung, Acta Mater. 62, 141 (2014)

[33] Y. Zhang, L. Zhu, A. Qi, Z. Lu, ISIJ Int. 50, 596 (2010)

[34] J.H. Zhou, Y.F. Shen, Y.Y. Hong, W.Y. Xue, R.D.K. Misra, Mater. Sci. Eng. A 769, 138471 (2020)

[35] X. Zhang, A. Godfrey, X. Huang, N. Hansen, Q. Liu, Acta Mater. 59, $3422(2011)$

[36] D. Jia, Y.M. Wang, K.T. Ramesh, E. Ma, Y.T. Zhu, R.Z. Valiev, Appl. Phys. Lett. 79, 611 (2001)

[37] Y.M. Wang, M.W. Chen, F.H. Zhou, E. Ma, Nature 419, 912 (2002)

[38] Y.H. Zhao, X.Z. Liao, Z. Jin, R.Z. Valiev, Y.T. Zhu, Acta Mater. 52, 4589 (2004)

[39] L. Lu, X. Chen, X. Huang, K. Lu, Science 323, 607 (2009)

[40] T. Hu, K. Ma, T. Topping, B. Saller, A. Yousefiani, J. Schoenung, E. Lavernia, Scr. Mater. 78, 25 (2014) 